\title{
Inspección de una losa de 70 años de un edificio en el Golfo de México
}

\author{
P. Castro-Borges ${ }^{1}$, M. Balancán-Zapata1 ${ }^{1}$, A. López-González¹, M. Córdova-Quintal².
}

${ }^{1}$ Centro de Investigación y de Estudios Avanzados del Instituto Politécnico Nacional, Km 6 Antigua Carretera a Progreso, C.P. 97310, Mérida, Yucatán, México.

${ }^{2}$ Facultad de Ingeniería de la Universidad Autónoma de Yucatán, Av. Industrias no Contaminantes por Periférico Norte, Apdo. Postal 15, Cordemex, Mérida, Yucatán, México

\begin{abstract}
Información del artículo
DOI:

http://dx.doi.org/10.21041/ra.v4

$\underline{i 3.70}$

Artículo recibido el 18 de junio

de 2014, revisado bajo las

políticas de publicación de la

Revista ALCONPAT y aceptado

el 24 de agosto de 2014.

Cualquier discusión, incluyendo

la réplica de los autores, se publicará en el segundo número del año 2015 siempre y cuando la información se reciba antes del cierre del primer número del año 2015.
\end{abstract}

(C) 2014 ALCONPAT Internacional

Información Legal

Revista ALCONPAT, Año 4, No. 3, Septiembre - Diciembre 2014, es una publicación cuatrimestral de la Asociación Latinoamericana de Control de Calidad, Patología y Recuperación de la Construcción, Internacional, A.C., Av. Zamná No. 295 entre 61 y 63 Fraccionamiento Zamná No. 295 entre 61 y 63 Fraccionamien Yucalpetén, Mérida, Yucatán,

alconpat.int@gmail.com, Página Web: www.mda.cinvestav.mx/alconpat/revista. Editor responsable: Dr. Pedro Castro Borges. Reserva de derechos al uso exclusivo No.042013-011717330300-203, eISSN 2007-6835, ambos otorgados por el Instituto Nacional de Derec no de Autor. Responsule de lálima Derecho de Autor. Responsable de la últin actualización de este número, Unidad de Informática ALCONPAT, Ing. Elizabeth Sabido
Maldonado, Av. Zamná No. 295 entre 61 y 63 Fraccionamiento Yucalpetén, Mérida Yucatán, México, C.P. 97248 , fecha de publicación: 30 de septiembre de 2014

Las opiniones expresadas por los autores no necesariamente reflejan la postura del editor. Queda totalmente prohibida la reproducción total Queda totalmente prohibida la reproduccion
o parcial de los contenidos e imágenes de la o parcial de los contenidos e imágenes de
publicación sin previa autorización de la ALCONPAT Internacional A.C.

\section{RESUMEN}

El muelle de Progreso alberga un edificio de setenta años de antigüedad, expuesto a un ambiente agresivo en el Golfo de México. Debido a la exposición a cloruros y la falta de mantenimiento, su losa mostró síntomas de corrosión y desprendimientos de concreto. En una inspección estructural previa se sugirió un costoso y poco comprensible método de reparación, lo cual hizo pensar a las autoridades portuarias en la demolición sin prever daños colaterales a otros elementos como columnas y vigas. Debido al nivel de deterioro, los autores de este trabajo sugirieron una segunda inspección antes de demoler, la cual se realizó en zonas representativas. El objetivo de este trabajo es discutir detalles y resultados de ésta y de la inspección previa, así como del diagnóstico, el cual indicó la necesidad de demoler partes específicas de la cubierta inferior de la losa y la sustitución de la armadura por CFRP.

Palabras clave: inspección; reparación; cloruros; técnicas electroquímicas.

\section{ABSTRACT}

The Progreso pier has a head which is a seventy year-old building that is exposed to an aggressive environment in the Gulf of Mexico. As a consequence of the chloride exposure and lack of maintenance, the slabs have shown strong deterioration symptoms. A previous structural inspection suggested a very expensive and non well understood method to repair the slab, which made the authorities to think about demolition in spite of the collateral damage to other elements like columns and beams. Because of the deterioration level, the authors of this paper suggested a second inspection before demolishing and it was performed on selected parts of the slab. The objective of this work is to discuss details and results of this and previous inspection and diagnosis. The new diagnosis indicated the need of demolishing specific parts of the lower concrete cover of the slab and the substitution of the reinforcement by CFRP.

Keywords: inspection; repair; chlorides; electrochemical techniques.

Autor de correspondencia: Pedro Castro Borges (pcb1963@gmail.com) 


\section{INTRODUCCION}

El edificio principal de la Autoridad Portuaria (API) se ubica en la terminal intermedia del muelle fiscal de Progreso que se encuentra en servicio desde 1941. Este edificio presenta problemas patológicos, principalmente desprendimientos y delaminaciones del hormigón debido a la corrosión del refuerzo en la mayoría de sus columnas, vigas y losas. Este edificio de cuatro niveles presenta problemas visibles debido a su uso, edad, reparaciones pobres y falta de mantenimiento. Debido a lo anterior API contrató una inspección para tener un punto de vista estructural y por durabilidad de la estructura completa. Sin embargo, los resultados causaron una desilusión a la API, debido a que la solución propuesta consistió en una reparación por parcheo, pero sin un conocimiento profundo de las causa del problema, y tampoco del origen de los daños. Debido a estos resultados, las autoridades pensaron en demoler completamente la losa sustituyéndola por una nueva, sin embargo, esta acción podría ocasionar un fuerte daño a otros elementos estructurales tales como columnas y vigas, y por supuesto un tremendo costo derivado no sólo de los gastos de reparación y construcción, sino también de las medidas logísticas que implican el movimiento de los equipos, muebles y personal a otras instalaciones. Como consecuencia de ello, los autores de este trabajo sugirieron un estudio más completo y detallado de durabilidad a fin de desarrollar una estrategia de reparación que pudiera salvar la losa y extender la vida útil remanente de todo el edificio sin gastos significativos por logística y construcción. Se realizaron pruebas de resistencia a la compresión, contenido de cloruros, potencial de corrosión y velocidad de corrosión para conocer la gravedad del problema y discernir sobre posibles reparaciones. La nueva propuesta consistió en un cuidadoso rediseño de la estructura de acuerdo a códigos modernos, sustituyendo el acero negro viejo por un uso consciente y selectivo de polímeros reforzado con Fibras de carbono (CFRP por sus siglas en inglés). El objetivo de este trabajo es discutir algunos detalles y resultados de los procedimientos propuestos durante la inspección, diagnóstico y reparación.

\section{EXPERIMENTAL}

La Figura 1 muestra fotos del muelle de Progreso y del edificio inspeccionado. Los cimientos del edificio están sobre los arcos, vigas y pilotes del muelle fiscal los cuales están hechos de hormigón masivo. Las vigas del muelle tienen acero inoxidable 304, sin fines estructurales como se ha discutido en trabajos previos (Castro et al, 2002). El edificio está en el centro de la cubierta del muelle principal y tiene una altura de $17.90 \mathrm{~m}$. El edificio está en servicio desde 1941, según reporta (Christensen, 1954).
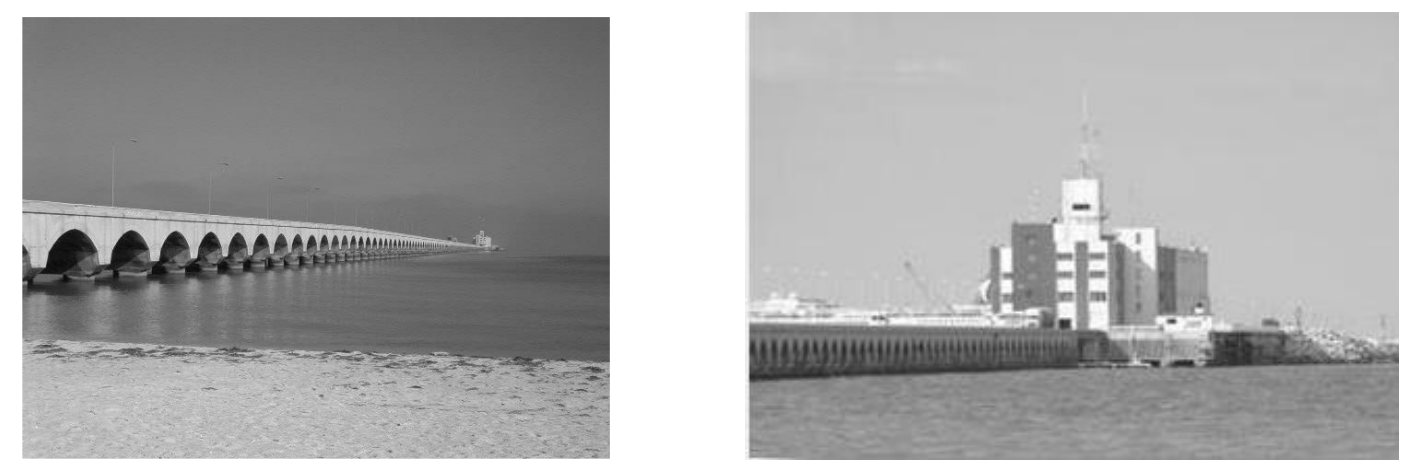

Figura 1. Fotos del muelle de Progreso y del edificio evaluado. 
Revista ALCONPAT, Volumen 4, Número 3, Septiembre- Diciembre 2014, Páginas 202 - 210

Se realizaron pruebas de resistencia a la compresión (f'c) (NMX-C-169-ONNCCE-2009), potencial de corrosión (Ecorr) (ASTM C876), velocidad de corrosión (icorr) (Andrade, 1996) y resistividad eléctrica (Rs) (Millard, 1993), así como de contenido de cloruros (Cl-) (ASTM C1152 ) y porosidad efectiva ( $\varepsilon$ ) (Fagerlund, 1986) mediante núcleos de hormigón.

La Figura 2 muestra un esquema de las Zonas seleccionadas para la inspección, denominadas Zona 1 y Zona 2. La Figura 3 muestra la losa de la Zona 1. Se seleccionaron estas áreas debido a que son representativas de las Zonas afectadas. La ubicación de la Zona 1 es al Noreste (NE) del edificio, sección de vientos predominantes marinos y área seriamente dañada, con presencia de grietas y desprendimiento del recubrimiento en varias partes. Esta Zona recibió mantenimiento hace ocho años a través de un sistema de parcheo en un $80 \%$ de su superficie. La Zona 2 está en el lado Noroeste (NO) y mostró mantenimiento previo de parcheo en aproximadamente $20 \%$ de su superficie. Visualmente la Zona 2 es una de las losas más conservadas, caso contrario a la Zona 1.

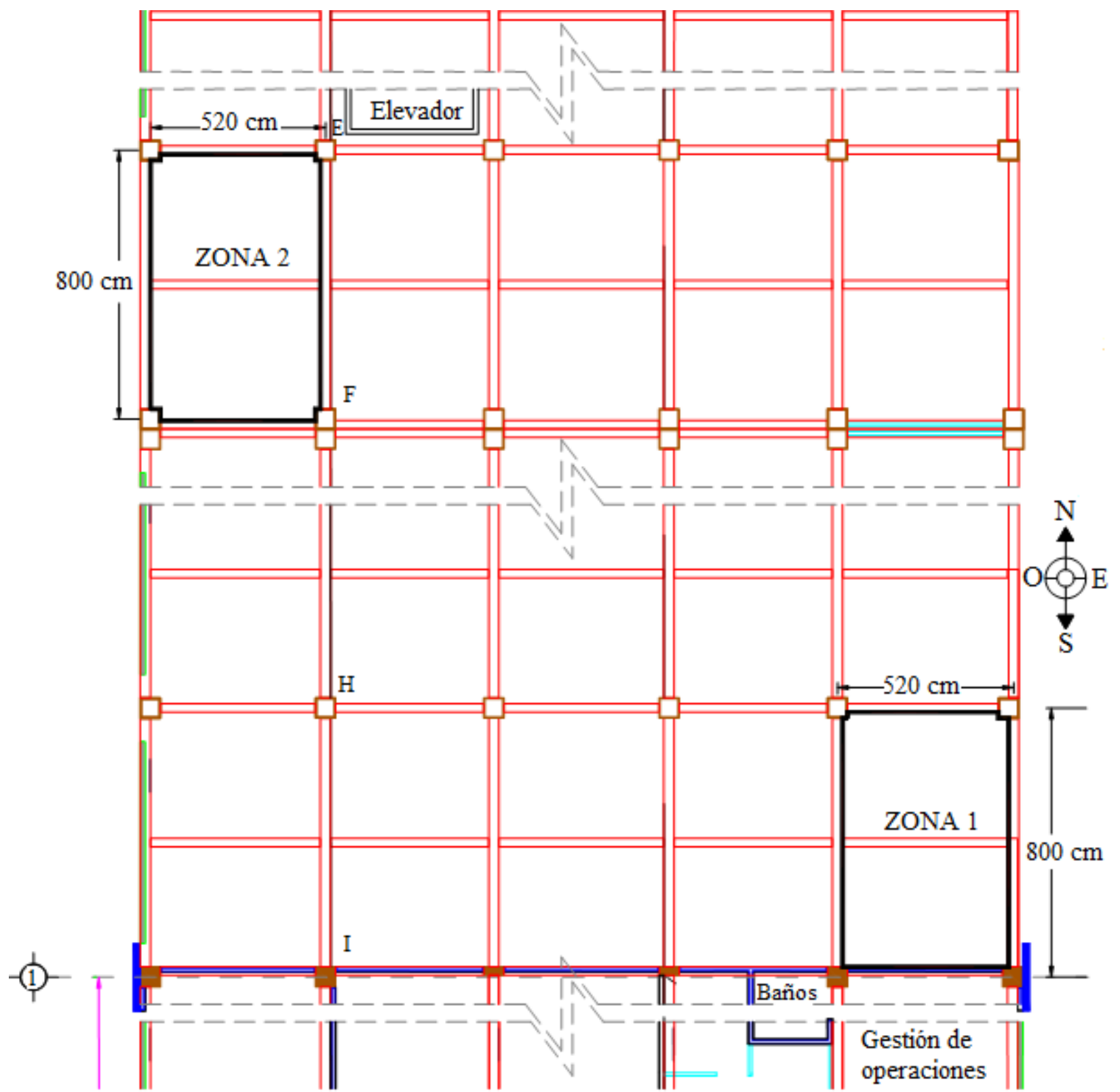

Figura 2. Esquema de las Zonas inspeccionadas en las losas de las Zonas 1 y 2 


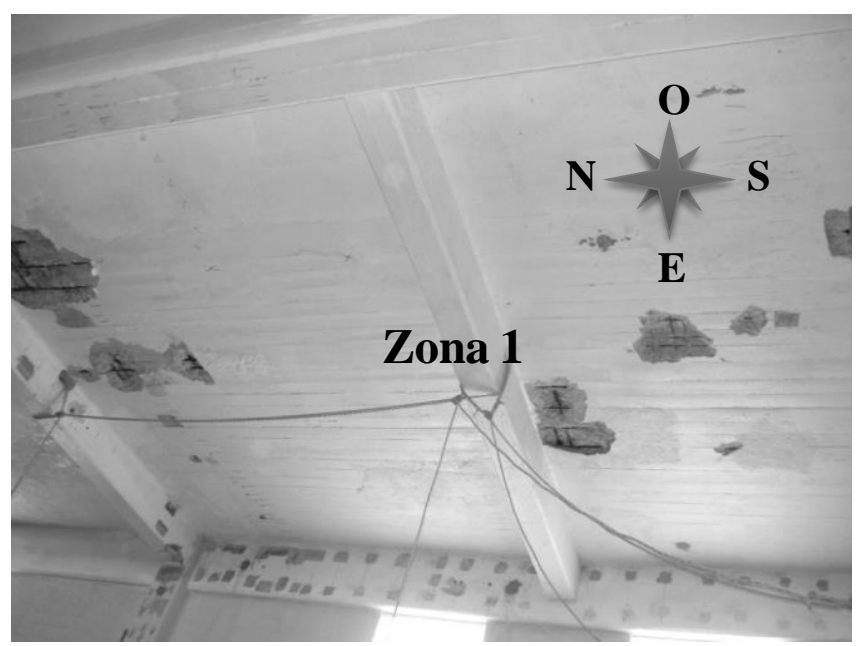

Figura 3. Foto de losas deterioradas en la Zona 1 que corresponde al NE (vientos predominantes)

\section{RESULTADOS}

\subsection{Potencial de corrosión}

Las Figuras 4 y 5 muestran la distribución de Ecorr en las losas. Las Zonas color rojo indican la mayor probabilidad de corrosión y por lo tanto la gravedad del problema. El efecto de los vientos predominantes se observa en la Zona 1. Las mediciones de Ecorr mostraron la posible distribución de las zonas con mayor o menor riesgo de corrosión y de desprendimientos del hormigón, en términos de su posición con respecto a los vientos predominantes. Los valores obtenidos permitieron la selección de lugares estratégicos para obtener los valores de velocidad de corrosión.

Losa Zona 1

Potenciales de corrosión ( $\mathrm{mV}$ vs $\mathrm{Cu} / \mathrm{SO}_{4}$ )

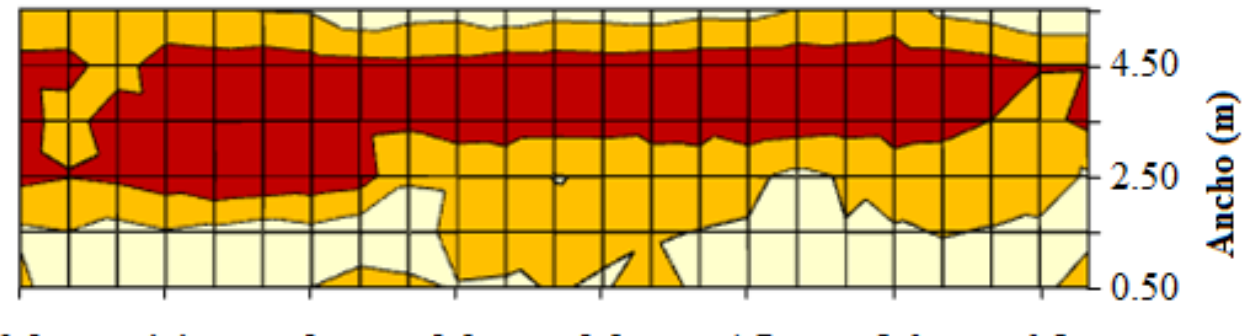

$\begin{array}{lrrrr}0.2 & 1.1 & 2 & 2.9 & 3.8 \\ \square-200--50 & & & \text { Londitud (m) } \\ \square-350--200 & & & \\ \square-500--350 & & & \end{array}$

Figura 4. Mapeo de potencial de corrosión de la losa en la Zona 1. 


\section{Losa Zona 2}

Potenciales de corrosión $\left(\mathrm{mV}\right.$ vs $\left.\mathrm{Cu} / \mathrm{SO}_{4}\right)$

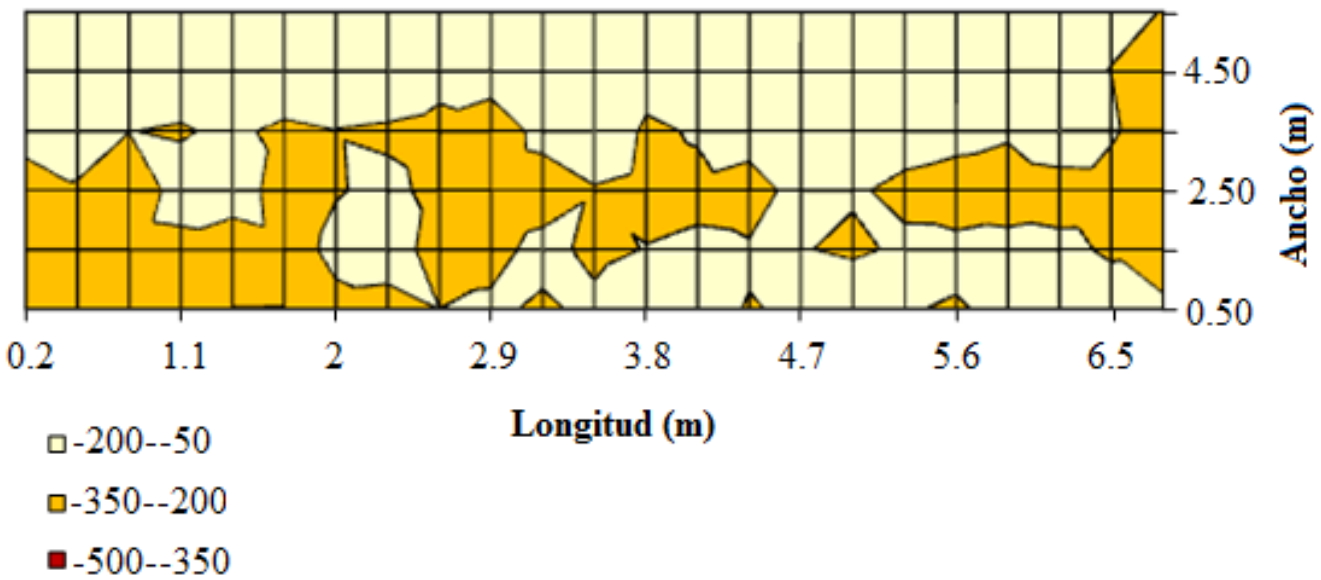

Figura 5. Mapeo de potencial de corrosión en losa en la Zona 2

\subsection{Velocidad de corrosión}

Las Figuras 6 y 7 muestran la distribución de la velocidad de corrosión en partes seleccionadas de la losa en la Zona 1 y en la Zona 2. Los resultados corroboraron los valores de Ecorr y sirvieron para detectar las áreas con mayor sensibilidad y probabilidad de desprendimiento. Los valores con mayor riesgo a presentar corrosión, de acuerdo a la literatura (Troconis et al, 1997), fueron detectados en donde existían zonas reparadas por parcheo. Este es un claro ejemplo de que una incorrecta reparación puede empeorar el problema.

\begin{tabular}{|l|l|}
\hline $\mathrm{i}_{\text {corr }}$ Insignificante & \\
\hline $\mathrm{i}_{\text {corr }}$ Moderada & \\
\hline $\mathrm{i}_{\text {corr }}$ Alta & \\
\hline $\mathrm{i}_{\text {corr }}$ Muy alta & \\
\hline
\end{tabular}

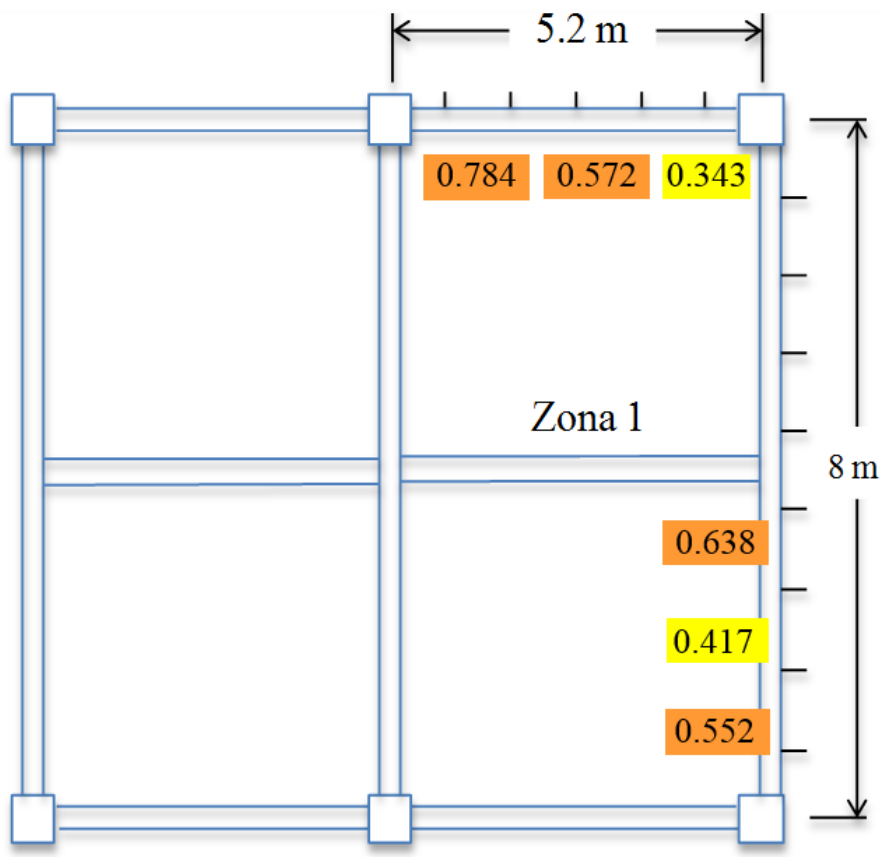

Figura 6. Distribución de la corrosión en $\mu \mathrm{A} / \mathrm{cm}^{2}$ para la Zona 1 de la losa, lado NE (vientos predominantes) 


\begin{tabular}{|l|l|}
\hline $\mathrm{i}_{\text {corr }}$ Insignificante & \\
\hline $\mathrm{i}_{\text {corr }}$ Moderada & \\
\hline $\mathrm{i}_{\text {corr }}$ Alta & \\
\hline $\mathrm{i}_{\text {corr }}$ Muy alta & \\
\hline
\end{tabular}

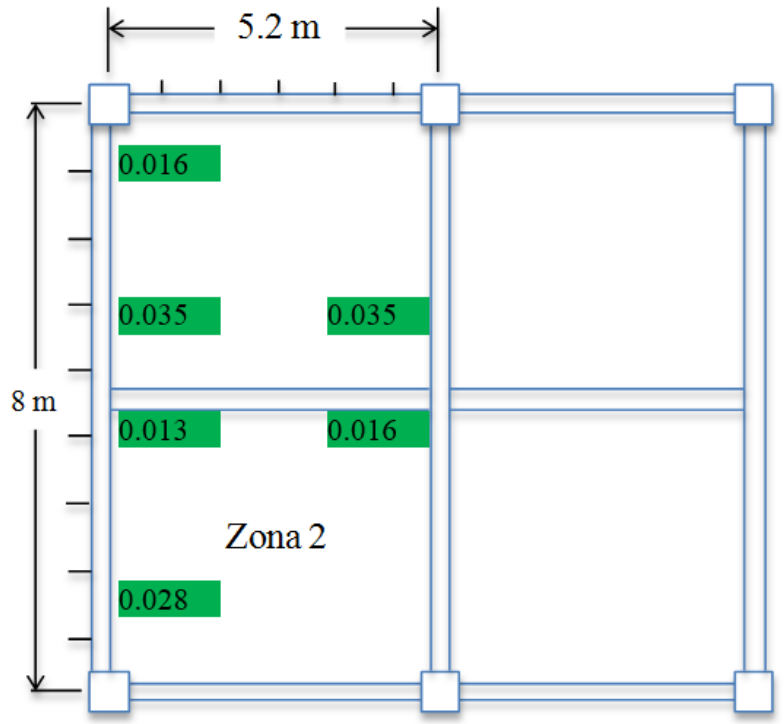

Figura 7. Distribución a la corrosión en $\mu \mathrm{A} / \mathrm{cm}^{2}$ para la Zona 2 de la losa (lado NO)

\subsection{Resistencia a la compresión}

La Resistencia a la compresión fue obtenida e interpretada de acuerdo a la norma NMX C 1693 y ACI 318. Uno de los valores representativos obtenidos para las losas fue de $30 \mathrm{MPa}$, que es una resistencia muy buena desde el punto de vista estructural, pero permeable desde el punto de vista de la durabilidad.

\subsection{Concentración de Cloruros}

La Figura 8 muestra un núcleo representativo para la extracción de cloruros. Es de notar la composición de este núcleo de la losa: mortero (parte superior), piedras (parte media) y hormigón (parte inferior). La concentración de cloruros se obtuvo en los tres materiales como se observa en la misma Figura 8. La forma y la intensidad del perfil de cloruro aportaron varias pistas para diseñar la estrategia de reparación.

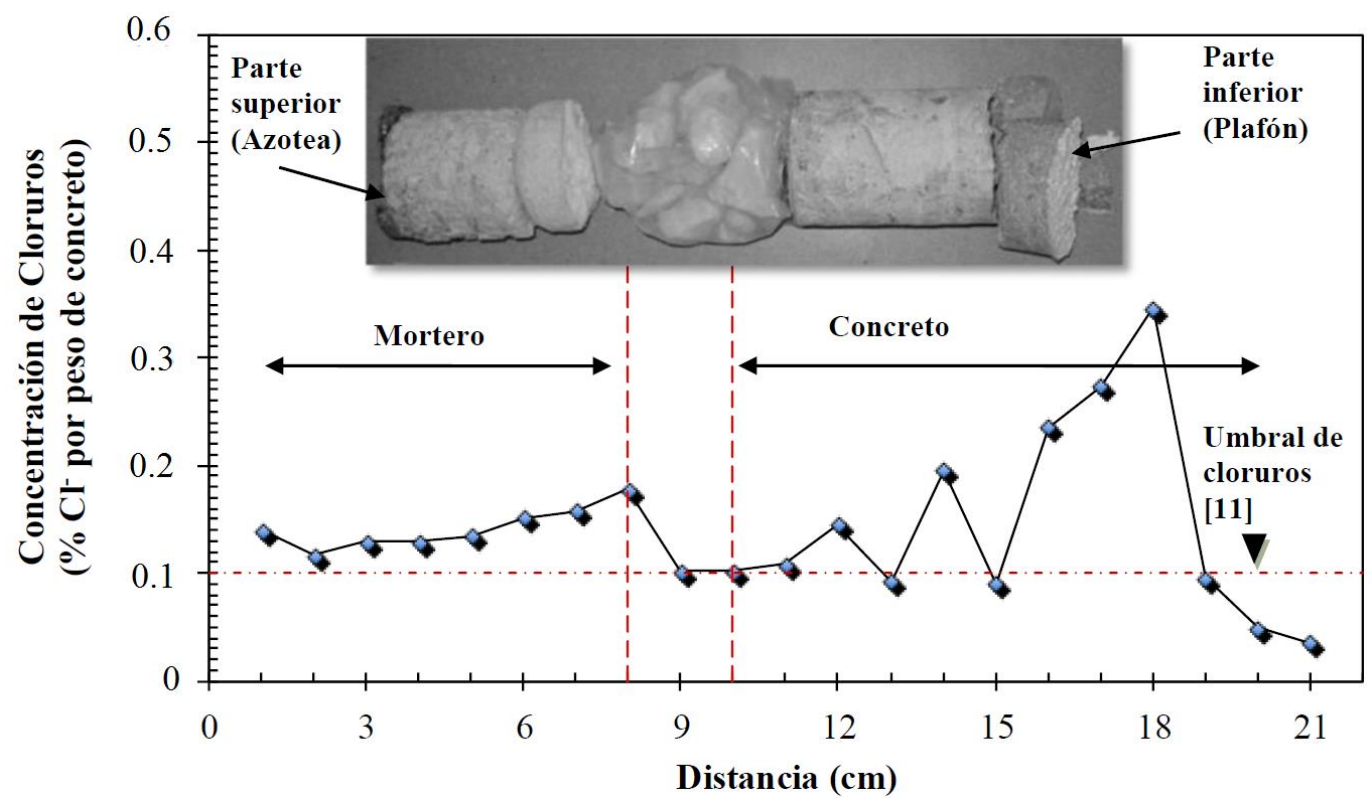

Figura 8. Perfil de Cloruros obtenido a partir de un núcleo representativo de la Zona 1 
Revista ALCONPAT, Volumen 4, Número 3, Septiembre- Diciembre 2014, Páginas 202 - 210

\subsection{Porosidad}

La porosidad efectiva $(\varepsilon)$ fue obtenida e interpretada de acuerdo al método de Fagerlund (Fagerlund 1986). Los valores obtenidos en las losas estuvieron entre 18 y $22 \%$ lo cual es elevado. Estos valores son característicos de un hormigón permeable.

\section{DISCUSIÓN}

\subsection{Mecanismos de Daño}

Hormigones similares a los que se usaron en las losas han sido expuestos durante varios años al mismo ambiente marino y se ha encontrado que el umbral de cloruros, para el inicio de corrosión, es de $0.11 \%$ por peso de concreto (Castro, 2001). Suponiendo que esta información es válida para este tipo de hormigón, la información electroquímica, junto con la distribución del perfil de cloruros hizo pensar que la corrosión del refuerzo es evidente y que la intrusión de cloruros debe ser controlada.

La Figura 8 muestra que la entrada de cloruros fue limitada por las capas superiores de piedras y mortero sobre la losa. Sin embargo, se observa un perfil bien definido desde la parte blanda (mortero) hasta la parte más interna de la losa. Esto es, que los primeros $10 \mathrm{~cm}$ de hormigón, detrás del eje neutro, están contaminados por cloruro y por lo tanto, provocando la corrosión del acero de refuerzo en el lado de flexión de la losa. La razón por la que el perfil de cloruros mostró un pico fuerte en la parte media de la losa podría estar relacionada con el hecho de que una vez que el edificio fue rehabilitado, se creó una restricción de puertas y ventanas para la entrada de cloruros. La condición de baja humedad de la nueva condición promovió a su vez una fuerte disminución del contenido de cloruro en la superficie de la parte blanda de la losa.

La losa fue recalculada siguiendo los criterios actuales y se encontró que el diámetro del acero de refuerzo podría tener una pérdida de sección de hasta el 33\% sin tener problemas estructurales. Desafortunadamente, las grietas, los productos de corrosión y desprendimientos de hormigón afectaron negativamente cualquier refuerzo. Por estas razones, se decidió retirar todo el refuerzo en el lado de flexión (momento de flexión positivo).

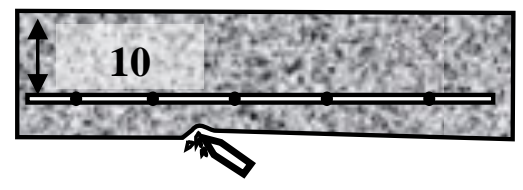

a) Remoción de concreto

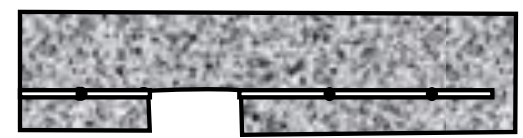

b) Retiro del acero de refuerzo

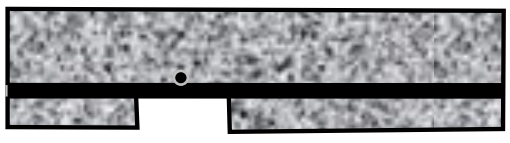

c) Sustitución del acero de refuerzo por CFRP

Figura 9. Esquema de remoción del acero de refuerzo y sustitución de CFRP.

\subsection{Método sugerido para las reparaciones}

La primera medida es evitar la entrada de más humedad y cloruros a través del uso de deshumidificadores, la apertura de tragaluces que permitan la entrada de luz solar, etc. Los elementos que muestran una condición crítica deben ser reparados mediante la eliminación del acero dañado en la Zona de flexión (parte central de la losa) y la colocación de bandas de CFRP (en ambas direcciones, $10 \mathrm{~mm}$ de ancho) como se muestra en la Figura 9. Todo el refuerzo corroído de las losas debe ser eliminado por decapado de unos $6 \mathrm{~cm}$ a lo largo de la superficie de la losa. Se colocarán dos capas de $1 \mathrm{~cm}$ de ancho de CFRP y distribuyéndolos de acuerdo al recálculo estructural de la losa el cual establece que esta fibra sea utilizada como refuerzo a la flexión. 


\subsection{Directrices para la inspección y reparación de estructuras similares}

Estructuras similares con problemas similares en las losas se pueden inspeccionar y reparar mediante los siguientes lineamientos:

a) Debe realizarse un estudio de durabilidad con pruebas químicas y electroquímicas.

b) Después de tener el diagnóstico de corrosión, se debe analizar una estrategia para la posible sustitución de la armadura.

c) Se debe realizar un análisis estructural de acuerdo con el uso real de la estructura y los códigos de construcción respectivos.

d) Proporcionar un proyecto mostrando paso a paso los procedimientos, para la sustitución de los refuerzos.

e) Realizar una prueba sobre la losa con el fin de comprobar si los procedimientos y los resultados se encuentran dentro de la expectativa.

f) Preparar un reporte posterior a la inspección basado en los resultados de la reparación.

\section{CONCLUSIONES}

Estas conclusiones se aplican a las condiciones de este trabajo. Cualquier extrapolación a otras condiciones diferentes debe hacerse con cuidado y bajo la responsabilidad del contratista respectivo y/o propietario.

- Se realizó un estudio de durabilidad en el edificio principal de la Autoridad Portuaria en el muelle de Progreso (a $2 \mathrm{Km}$ de la costa) en un ambiente tropical marino. Los resultados de las losas fueron discutidos en este trabajo, ya que requieren una actuación más urgente.

- Se describió el mecanismo de deterioro por cloruro y corrosión. El techo estaba protegido de la fuerte acción de los cloruros por las capas adicionales con las que cuenta (piedras y mortero). Sin embargo, la región blanda sin protección (mortero) permitió la entrada de los cloruros y la corrosión de la armadura.

- Los ensayos electroquímicos fueron un instrumento importante para determinar las causas y la gravedad del problema.

- Con el fin de evitar más problemas de corrosión, se llevó a cabo un análisis estructural y se hizo posible un plan para eliminar el acero de refuerzo de flexión en la parte inferior de la losa de hormigón. Este análisis se publicará en otro trabajo.

- Debido a las condiciones de deterioro, se propuso un método de sustitución de las barras de refuerzo de flexión por el uso selectivo de CFRP. Se proporcionó una breve descripción de este método.

- El contrato para el plan de reparación se estaba asignando al cerrar este artículo

\section{AGRADECIMIENTOS}

Los autores agradecen el apoyo parcial del CINVESTAV y CONACYT en algunas partes de este trabajo. Un reconocimiento especial a la API por su patrocinio. Las opiniones y puntos de vista son los de los autores y no necesariamente de las organizaciones de apoyo. 
Revista ALCONPAT, Volumen 4, Número 3, Septiembre- Diciembre 2014, Páginas 202 - 210

\section{REFERENCIAS}

ACI 318. Building Code Requirements for Structural Concrete and Commentary, American Concrete Institute.

Andrade C., Alonso, C. (1996) Corrosion rate monitoring in the laboratory and on-site, Construction and Building Materials, Vol. 10, No. 5, pp. 315-328

ASTM C876. Test Method for Half-Cell Potentials of Reinforcing Steel in Concrete

ASTM C-1152. Standard Test Methods for Water-Soluble Chloride in Mortar and Concrete

Castro P, Troconis O., Moreno E., Torres-Acosta A., Martínez-Madrid M y Knudsen A. (2002)

Performance of a 60-year-old concrete pier made with stainless steel reinforcement in Mexico.

Materials Performance Vol. 4, No. 10, pp. 50-55

Castro P.: The chloride threshold for corrosion onset of reinforced concrete in two tropical marine micro-climates of Yucatán-México. In: N. Banthia, K. Sakai, and O.E. Gjørv (eds), Third International Conference on Concrete under Severe Conditions. Environment and Loading, The University of British Columbia, Vancouver, Canada Vol. 1 (2001), 151-158.

Christensen A., (1954) Pier at Progreso, 50 Years of Civil Engineering, Christiani \& Nielsen, Copenhagen, Denmark,.

Fagerlund, G. (1986) On the Capillarity of Concrete, Nordic Concrete Research, No. 1, Oslo, paper No. 6.

NMX-C-169-ONNCCE-2009. Industria de la Construcción-Concreto-Extracción de Especímenes Cilíndricos o Prismáticos de Concreto Hidráulico Endurecido.

Millard S. G. (1993), Corrosion rate measurements of in situ reinforced concrete structures". in: Proceedings of the Institute of Civil Engineer, Structures and Building., Vol. 99, pp. 84-88.

Troconis O. y Miembros de la Red DURAR (1997), Manual de Inspección, Evaluación y Diagnóstico en Estructuras de Hormigón Armado, CYTED, Programa XV.b, Durabilidad del Refuerzo, 207 p. 